\title{
Children's earthquake preparedness and risk perception: a comparative study of two cities in Turkey, using a modified PRISM approach
}

\author{
Ayse Yildiz, Richard Teeuw, Julie Dickinson, Jessica Roberts
}

\begin{abstract}
Understanding children's risk perception and investigating the underlying factors are important aspects of examining how children interpret and respond to earthquake events. This research examines children's perceptions of earthquake risk and preparedness level in the Van and Kocaeli provinces of Turkey. A mixed-method approach is used, with questionnaires and interviews, as well as the Pictorial Representation of Illness and Self Measure (PRISM) technique. The results show that the majority of the school children did not attend disaster education programs, even if they were living in an area of high seismic risk. The sampled children were generally aware of the earthquake risk in their home area. However, their levels of preparedness were low. A consistent relationship was found between: (1) earthquake risk perception, (2) earthquake awareness, (3) factual knowledge of preparedness, (4) importance of preparedness, and (5) earthquake education programs. The results indicate that children who participated in earthquake education programs had higher earthquake awareness, foresee future earthquake occurrence and the potential causes of injury. Also highlighted was the importance of information sharing within families, as a factor influencing children's earthquake risk perception and preparedness. The results are considered of value for actors in the disaster risk reduction sector. They provide perception insights to improve the communication and dissemination of information about earthquake risk.
\end{abstract}

Keywords: children; earthquakes; risk perception; preparedness; PRISM; Turkey 


\section{INTRODUCTION}

2 Earthquakes are one of the most deadly natural disasters, often causing devastating damage

3

4 and loss of life. Globally, earthquakes have caused huge economic losses and thousands of deaths. Between 1998 and 2018, earthquake disasters killed 752,498 people and injured around 1,574,000 according to EM-DAT (2019) statistics. The 2015 Nepal Earthquake (7.8 $\mathrm{M}_{\mathrm{w}}$ ) killed about 9,000 people, injured 23,000 people and destroyed more than 250,000 buildings (Liang \& Zhou, 2016); the 2011 Tōhoku earthquake (also known as the Great East Japan Earthquake) (9.1 $\mathrm{M}_{\mathrm{w}}$ ) killed more than 20,000 people, and displaced 465,000 (Amadeo, 2019); the 2010 Haiti earthquake $\left(7 \mathrm{M}_{\mathrm{w}}\right)$, killed around 316,000 people, injured 300,000 and displaced 1.3 million; and the 2008 Wenchuan Earthquake killed at least 69,195 people and injured 374,177 (USGS, 2019).

Turkey is a country prone to a range of natural hazards due to its geological setting and its climate: these include earthquakes, landslides, floods, and wildfires. Of all the natural disasters to affect Turkey since 1900, earthquakes have caused the greatest impact on population and infrastructure, with a large-scale earthquake occurring approximately every seven years (Ozmen, 2000; EM-DAT, 2019). Earthquake events account for 55\% of all losses of life and property attributed to natural hazards in Turkey (Ersoy \& Kocak, 2016), close to double the amount of those incurred from landslides (30\%) and 7x more than those resulting from flood events $(8 \%)$. In total, since 1950, more than 33,000 people have lost their lives due to earthquakes (EM-DAT, 2019). The most recent devastating earthquakes in Turkey's history have been the 2011 Van earthquake (7.6 Mw), which killed more than 600 , injured more than 2,000 people, and damaged more than 49,000 buildings (AFAD, 2014), and the 1999 Marmara earthquake (also known as the Kocaeli earthquake) (7.4 Mw), which caused more than 17,000 deaths, 43,953 injuries and cost more than 12 billion USD (Holzer, 2000). Specifically, Turkey is situated at the upper levels of child mortality due to earthquakes (Ersoy \& Kocak, 2016). This is important because $34.5 \%$ of the population in Turkey is between 0 and 14 years old based on 2018 data from the Turkish Statistical Institute in 2019. For example, the 1999 Marmara earthquake caused 'heavy damage' to 43 schools and 'slight to moderate damage' to 381 schools leading to schools in the affected areas being closed for four months (Erdik et al., 2003; Ersoy \& Kocak, 2016). Furthermore, in the Bingol Earthquake, ten schools were heavily damaged, and four schools completely collapsed (Çetin et al., 2003; Ersoy \& Kocak, 2016). 
The 1999 Marmara earthquake was a pivotal point for Turkey's disaster management system: the extensive damage and many fatalities highlighted the need to overhaul disaster management in Turkey (AFAD, 2018a). Consequently, many measures aimed at disaster risk reduction were taken in Turkey's educational and socioeconomic sectors to minimize the negative effect of future earthquakes (AFAD, 2018a). As Merchant (2015) argued, this should be not only responsibility for the Turkish government and its agencies but also a responsibility for families and individuals. Consequently, public initiatives should be encouraged and engaged in the decision making process.

Despite the need for better disaster management in Turkey to minimise the risk of earthquakes, without an understanding of how the general public perceives the risk of earthquakes, even the most well-designed policies and procedures may not lead to the desired results. Because public risk perception is an essential part of the disaster risk reduction process (Frewer, 2004; Slovic, 1987; Santos-Reyes et al., 2017), policy makers the world over have started to include the public's views on risk perception in their policy making. Knowing how the public perceives risk is important as it provides an insight into how and why people respond to hazards in the way that they do (Slovic et al., 2000; Lindell \& Hwang, 2008; Lindell \& Perry, 2012; Bodoque et al., 2019). To ensure that the impact of earthquakes is limited, there is a need to understand what factors affect an individual's subjective judgement on what actions will help them cope better with a major earthquake event. Understanding such influences will then enable both policy and practice to focus on ensuring appropriate strategies are put in place in the future. However, risk perception is a highly interpretive and dynamic process (Hurmen \& McClure, 1997; Sjöberg, 2000; Paton et al., 2000), with disaster management experts and general public often having different understanding of hazards and risk (Sjöberg, 1999; Dwyer et al. 2004). While public risk perception is generally driven by economic interest, intuitive biases and cultural values (Slovic, 1987; Sjöberg, 1999), experts' risk perception tends to be more a product of analytic, objective and rational risk assessments (Kasperson et al., 2000; Slovic, 1987; Sjöberg, 1999).

In recent years, there has been increased research into earthquake disaster risk reduction, aiming to raise awareness and reduce the possible effects of future earthquakes (Tucker, 2013; Becker et al., 2014; Paton et al., 2015; Murakami et al., 2016; Becker et al., 2017; De Pascale et al., 2017; Santos-Reyes et al., 2017; Doyle et al., 2018; Han et al., 2020). At the policy level, both the Hyogo Framework for Action (2005) and Sendai Framework for Disaster Risk Reduction (2015) have emphasized the importance of public awareness and preparedness, 
encouraging individuals and communities to undertake preparedness activities. Some of the research findings suggest that the relationship between risk and preparedness perception is null or weak (Miceli et al., 2008). Some researchers have found a relationship between risk perception and preparedness (Kalaca et al., 2007), while others found that there is not a direct link between the two (Mileti and Fitzpatrick 1992; Lindell and Whitney 2000). Rustemli and Karanci (1999), in a study from Turkey, found that correlation between anticipation of earthquake-related damage and earthquake preparedness was not statistically significant. Furthermore, while the correlation between earthquake expectation and preparedness is statistically significant, it is very low with a correlation coefficient $r=.09$. Relatively few studies have specifically examined perceptions of earthquake risk and preparedness, and many have focused solely on adult perceptions. Although adult perceptions may have a beneficial influence on children's perceptions of earthquake risk and preparedness, this does not give a robust insight into children's own experience (Walker et al., 2010): the perceptions of children have been found to be considerably different to those of adults.

\section{Children and disasters}

The United Nations International Strategy for Disaster Reduction (2011) declared that children are the group most affected by disasters, with approximately 175 million children affected by natural disasters annually (Dyregrov et al., 2018). Children are more vulnerable to an emergency event than any other social group, a factor of their behavioural and psychological development level, physical size and partial or complete dependence on adults (Zahran et al, 2008). In addition, it is argued that children's physical, social and mental capacities experience rapid development, which can result in the effects of disasters being even greater for children, relative to adults (Taylor \& Peace, 2015). Despite their vulnerability, children can play an important role in earthquake preparedness and response, by communicating risks, participating in decision-making processes, and undertaking disaster risk reduction actions for their families and communities (Tanner, 2010; Anderson, 2005). Children can help their communities before and after a disaster, they can be agents of change within their communities, and they can be actively participant in preparedness activities in their schools, homes, and communities (Mort et al., 2016; Bodoque, 2019).

The study of children and disaster contexts is particularly important because it sheds light on the development of disaster management, as well as aspects of complicated adaptive systems involved in education, protecting and empowering children (Peek, 2008). Children need to 
understand and be ready for natural hazards as much as adults (Finnis et al., 2004; Walker et al., 2010) in order to build a resilient future (Peek, 2008). The information gained in this area can help families, communities, and nations to better mitigate, respond to, and cope with future hazardous events. Disaster risk perception studies with children can also inform decisionmakers and leaders with regard to better engagement with children and how best to allocate disaster management resources (Hayward, 2012; Peek et al., 2018). Children's disaster awareness and their education for preparedness is, therefore, an integral part of disaster risk reduction studies. Some studies focused on the different attitudes and perception of earthquakes related to education (Santos-Reyes et al., 2014; Rahman, 2019). They indicate that disaster education is important in enhancing perception of earthquake and knowledge (Shaw et al., 2004; Graham et al., 2006; Shiwaku et al., 2007; Mutch, 2014; Torani et al., 2019). In a study carried out at high schools in the New Zealand towns of Inglewood, Stratford, and Opunak, it was found that participation in hazard awareness education increased children's knowledge of safety behaviour (Finnis et al., 2010). Also some studies have focused on children's disaster experience. For example; Yasuda et al. (2018) indicated that children who experienced a disaster in the past have a higher awareness of threats and prevention; however, this effect was short-lived. Some other researchers indicated that the role of family is an important indicator on children's reactions to natural disasters (Repetti et al., 2002; Proctor et al., 2007). Also Najafi et al. (2018) indicates that feelings, emotions, and social norms are likely to influence children's beliefs in disaster contexts.

There are only a few studies on children's earthquake risk perception and preparedness, especially in the context of disaster risk reduction in Turkey. In recent years the Turkish government has accelerated initiatives to create an earthquake-resilient society. That is particularly with the recent widespread growth of disaster awareness programs to prepare children better for hazardous events, by the Turkish Ministry of National Education and the Disaster \& Emergency Management Presidency. However the question still remains about how Turkish children interpret earthquake risk in their home district. This study aims to fill that knowledge gap: we examine the earthquake awareness, risk perception, and level of preparedness of Turkish children. This will enable us to learn more about underlying processes at the heart of family and community resilience, enabling better preparedness and response with future earthquake events. It is intended that the research findings will contribute to the development of child-centred disaster risk reduction, with regard to the ways that children prepare for and respond to earthquakes. This research also explores the many diverse factors 
that have an influence on children's earthquake risk perception and preparedness. In this research paper, the sections are presented in the following order: study areas, methods, results, discussions, and conclusions.

\section{STUDY AREAS}

The study areas for this research are the Turkish cities of Golcuk (Kocaeli province) and Ipekyolu (Van province). The research design is based on a comparative analysis, as in Bryman (2012). Many researchers have suggested that comparative studies are useful in order to be an important aspect of understanding the failure or success of a given intervention (Joppe, 2000).

The two cities selected for this study were chosen first because of their location on seismically active fault lines and secondly due to their varied levels of socioeconomic development. Due to their geological position, both cities have in the last 20 years experienced devastating earthquakes: 1999 in Marmara (Kocaeli) and 2011 in Van (AFAD, 2018a). According to the SEGE (2011) socio-economic development ranking for the 81 provinces in Turkey, Kocaeli is ranked 4 th, while Van is ranked $75^{\text {th }}$.

Despite much debate over whether or not socioeconomic factors have an influence on disaster preparedness (Fothergill and Peek, 2004), Turner et al (1986), Bradford et al. (2012) and Hal et al. (2016) all report finding that higher income levels have a positive impact on levels of preparedness due to a rise in public risk perception. However in contrast, White, (1974); and Peacock et al., (2012), both found no influence. Also, Lamson (1983) indicated that people of lower socioeconomic status are more likely to have hazardous or risky occupations, and they thus might employ coping mechanisms to deal with it. Furthermore, some studies found that people from low income have greater risk perception (Pilisuk et al., 1987; Palm \& Carroll, 1998) and people from lower socioeconomic status tend to minimize or deny the risks (Vaughan, 1995). 


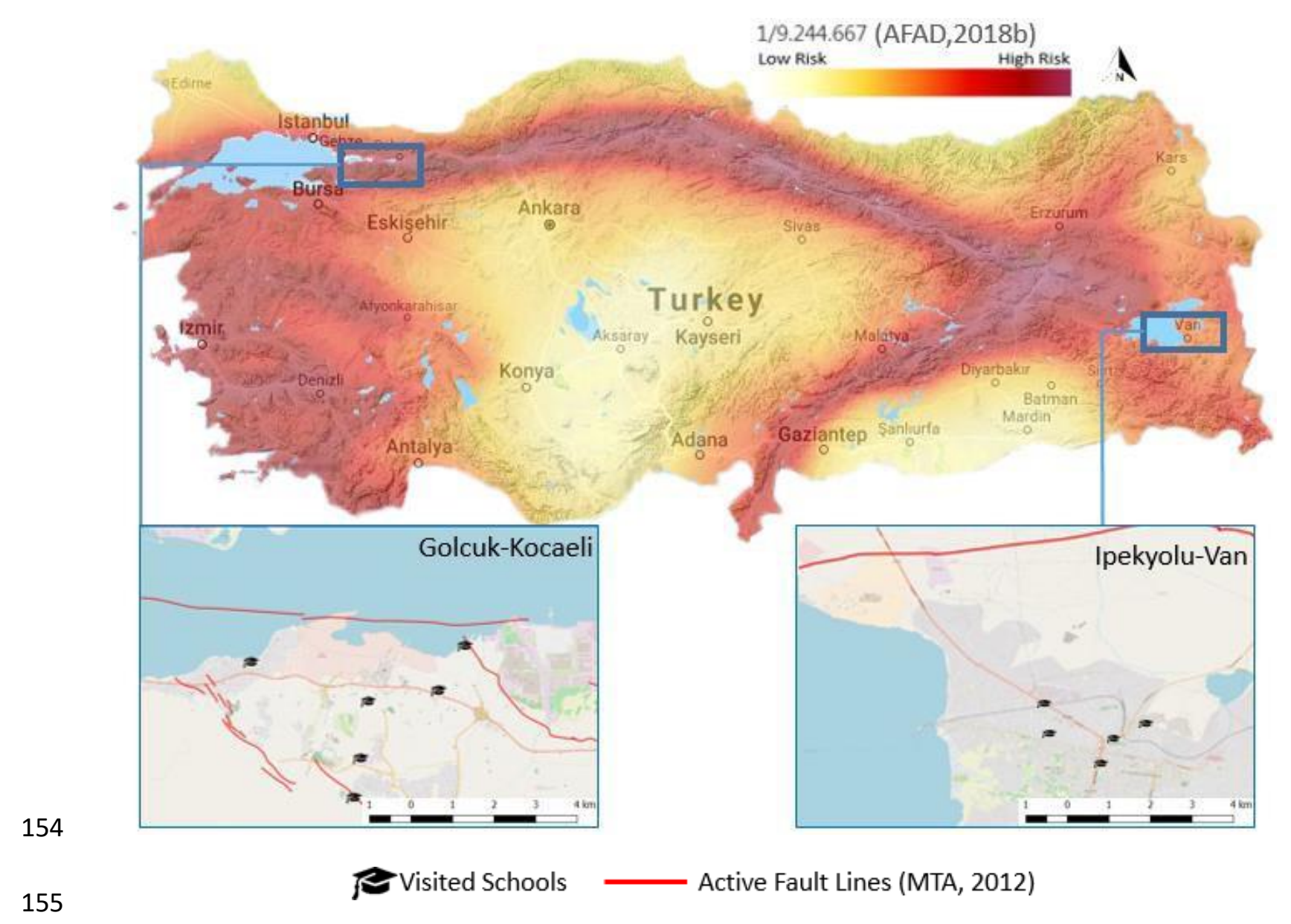

156 Figure 1. Turkey earthquake hazard map and visited schools (map sources: Open Street Map; 157 MTA, 2012; AFAD, 2018b).

\section{METHODS}

159

160

\subsection{Overview of the Design}

The current research was designed to provide information about Turkish school children's levels of earthquake awareness, risk perception, and preparation. In total, 809 participants were assessed in the cities of Kocaeli and Van. Each participant completed the same questionnaire (comprised of both the PRISM techniques and validation questions). In addition to the questionnaires undertaken, separate interviews were carried out with 100 of the same children surveyed, to explore participants' reasons for their questionnaire responses. Children were selected to be the focus of this study because children as a target population have received limited attention in studies of earthquake risk perception, yet children remain one of the most vulnerable groups in disasters. In this research, the attempt was made to contribute to child centred disaster management studies. 
In this research a mixed methods approach was used. The collection and analysis of both quantitative and qualitative data was selected in order to increase the rigor of the research by combining multiple measures, theories, perspectives and validation checks to ensure results were consistent (Perlesz and Lindsay 2003; Creswell and Clark, 2017). A mixed approach combines both numerical measurements and more in-depth evaluation of participant knowledge and opinion to maximise the strengths of each technique, in turn increasing the validity of the results, and adding multi-level perspectives, offering a more complementary and complete understanding of the research questions (Stentz et al, 2012). This was important in this research because we wanted to better understand children's different points of view, give them voice and ensure findings based on their experiences. The triangulated approach was taken, combining the use of questionnaires, PRISM and a series of separate interviews, allowing for the cross-comparison of data sets (Bryman, 2012).

\subsection{Sampling and data}

Data collected for this research formed part of a three year longitudinal study carried out to assess preparedness and risk perception of children aged 11-14. The age bracket of 11-14 years was selected in line with the ethics policy of Turkish Ministry of National Education and the University of Portsmouth. The ethical guidelines restricted participating children under the age of 11. Therefore to enable the three year longitudinal study, the first surveyed children were selected from Grade 5 and Grade 6 (11-14 years old).

The sampling strategy was driven firstly by researchers and secondly by the Turkish Ministry of National Educations in the two cities, along with the school authorities. On request, the Turkish Ministry of National Education gave permission for the survey to be run in 6 out of 24 of their government-run schools (for grades 5, 6, 7, 8) in Golcuk (Kocaeli), and 5 out of 56 in Ipekyolu (Van). Each individual school was selected for participation based on class availability. Individual teaching classes in which the survey would be carried out were selected by school managers. Only classes not undertaking core revision subjects on the days of the survey were available to participate in this survey. Core subjects are maths and science, Turkish language, social studies, foreign language, religion and moral lessons, art, sports and elective courses. When permission for a school survey was gained, the families of the sampled children were sent an information letter in their child's school bag, explaining the survey and requesting their signed permission for their child to participate in this study. Before starting this survey, the school children were told about the purpose of the study, and then their right to participate, 
or not participate, in the research was explained. Individuals were encouraged to answer the questions, and to ask for clarity if there was anything they found difficult about the research.

In this study, questionnaire data were collected from 809 children in the cities of Van $(n=384)$ and Kocaeli $(n=425)$, from October to November 2018. This sample size follows the guidance of Krejcie \& Morgan (1970), who indicate that a sample size of 384 is sufficient for a population size of more than 1,000,000. According to the Turkish Statistical Institute (2019), the population of Golcuk (Kocaeli) is 162,584, and for Ipekyolu (Van) it is 312,244. In 2018, the total population of 11-14 years old children (grades 5 and 6) in the 11 schools selected were: 1740 in Golcuk (Kocaeli), and 2398 in Ipekyolu (Van).

Following the questionnaires, three or four children from each participating class at each school were interviewed. The interview questions aimed to further investigate how children perceive earthquake risk and the importance of preparedness. The selection of children for the interview was dependent on each child's availability and time. The total 58 children from Golcuk (Kocaeli) and 42 from Ipekyolu (Van) were interviewed from the same participating classes that engaged in the questionnaires. The sample size was determined by the possible maximum number of students from each class to make valid inferences about the total population and generalize the findings. Britten (1995) indicates that large qualitative studies generally involve around 50 or 60 interviews.

\subsection{Measures}

Various methods can be used to measure risk perception and there is no agreed standard. The most common method is based on questionnaires about the likelihood or the probability of an event happening in the near future (Mileti \& Fitzpatrick, 1992; Lindell \& Whitney, 2000) within an unspecified time period (Siegrist \& Gutscher, 2006). Some of the scenarios assume a future event causing harm and injury to oneself, one's household, a friend, or a neighbour (Tekeli-Yeşil et al., 2010). Other scenarios examine the likelihood of damage to a respondent's property (Lindell et al., 2009). The mixed methods used in this research were: the Pictorial Representation of Illness and Self Measure (PRISM), close-ended yes-no questionnaires, Linkert scale questionnaires, and interviews.

\section{The Questionnaire and Pictorial Representation of Illness and Self Measure (PRISM)}

For the quantitative data collection, the PRISM technique, along with Linkert scale and close ended yes-no questions were applied. The close-ended questionnaire used in this research was 
adopted from that used in Ronan and Johnston (2001), Finnis et al. (2010), and in the Turkey Disaster and Emergency Management Presidency disaster awareness survey (Bursa AFAD, 2018). To find the most appropriate method, similar studies were reviewed from the EBSCO (2019) database. From this review it was decided that questionnaires were well suited for the purpose of this study because questionnaires provide a relatively efficient and quick way to gather information from large samples.

This research is innovative in its use of the PRISM technique to understand school children's earthquake risk perception and their preparedness. The initial aim of the PRISM technique developers, Tom Sensky and Stefan Buchi, was to develop a simple visual method to assess patient's perceptions of their health and coping capacity (Buchi et al., 1998; Buchi et al., 2002). PRISM is a simple visual instrument of aggregating and eliciting personally salient information, and depends heavily on defining subject, object(s) and context (Büchi et al, 1998). According to Sensky \& Büchi (2016), applying PRISM techniques gives participants a wider ability to explain themselves. The reliability of the PRISM technique is high with test-retest reliability $\mathrm{r}=0.95, \mathrm{p}<0.001$ and interrater reliability $\mathrm{r}=0.79$, p<0.001 (Buchi \& Sensky, 1999; Buchi et al., 2002). In 2013 Parham et al. (2015) used a modified PRISM technique with school children in Dominica to assess their multi-hazard risk perceptions relative to changes in their geography teaching curriculum. Their results indicated that school children have understood and engaged well with PRISM, and support the validity of data obtained using PRISM.

The reason for using PRISM in this Turkish study is that it provides a simple visual way to measure the perceived effect of hazard in the respondent's current life as well as evaluating the importance of hazard preparedness, by asking the participant to identify where to place their preferred choices on the PRISM template (Figure 2). A paper and pencil version of PRISM was used in this research. Children were told to imagine that A4 sheet of paper represents their life, and the circle on the bottom right hand corner represents themselves (Figure 2). Then they were asked where to locate threats of (mentioned) hazards in their life and the importance of preparedness on the PRISM template related to "self" circle. The distance between the centers of the "self" circle and the crosses indicating the threat and preparedness for earthquakes ranged from 0 to $27 \mathrm{~cm}$, and this measured distance was used for statistical analysis, with higher distances indicating lesser threats in their life (Figure 2).

\section{PRISM Instructions}


The participating school children were given the following instructions to respond to using the PRISM template illustrated in Figure 2.

i. I would like to understand better how natural hazards (earthquake, flood, landslide, storm, and wildfire) in your local area affect your life at the moment.

ii. I would like you to imagine that this white template represents your life as it is now.

iii. The circle in the bottom right-hand corner represents your 'self', and the cross $(X)$ represents (mentioned) hazard.

iv. Where would you put the (mentioned) hazard to reflect its threats to your life at the moment?

v. Where would you like to put (mentioned) hazard to reflect its importance of preparedness in your life at the moment?

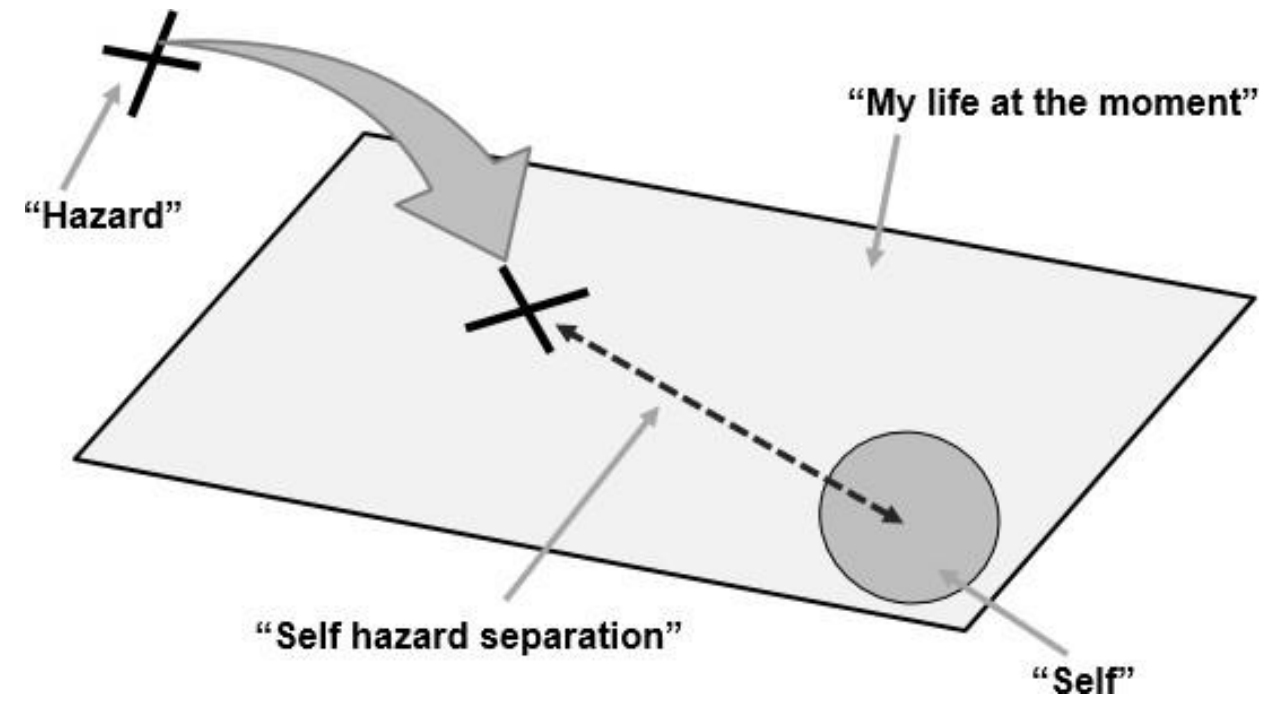

276276

277 Figure 2: An example of a completed PRISM sample. The line represents a measurement of 278 the self/hazard separation (SHS) distance. Terms translated to English for publication (Yildiz, 279 2019).

\subsubsection{Questionnaire for Earthquake Awareness and Risk Perceptions}

Participating school children were asked about the future likelihood of earthquake occurrence in their local area, and likelihood of causing injury. Responses were gathered using a threepoint Likert scale, as in the study of Finnis et al. (2010), which focused on children's natural hazard perception in New Zealand. Using yes/no questions, children were asked if they knew any active earthquake faults in their district, if they were aware of any earthquake risk maps, 
and if they were able to interpret those maps to understand their earthquake awareness. These questions were adopted from (Bursa AFAD, 2018). Using PRISM, children were asked "Where would you put earthquake hazard to reflect its threats to your life at the moment?" to measure their earthquake risk perception.

\subsubsection{Questionnaire for Preparedness}

To examine factual knowledge for preparedness; the school children were asked to identify the actions they felt were the most appropriate responses for earthquakes. They were instructed that they could select more than one action to represent the appropriate response for earthquake hazard. For earthquake preparedness knowledge, correct actions are a) Stay inside, taking cover under beds, etc. b) Curl into a turtle shape and protect your head (duck, cover, hold); incorrect responses are, c) Run outside, d) If you are outside, find a tree or something sturdy to grab on to e) Stay right where you are and wait for it to be over. The correct answers are promoted by the Disaster and Emergency Management Presidency of Turkey (AFAD, 2013).

To examine physical preparedness; children were asked questions regarding plans and practices, and preparedness measures, and hazard adjustment adoptions on close-ended yes-no questions. Regarding information on response plans and practices, children were asked if they or a member of their close family had previously done any of the following: compiled a household emergency plan, practiced an emergency plan at home, practiced an emergency plan at school, identified potential emergency exits, identified assembly areas, switched utilities, and planned where to meet or leave a message in an emergency. For preparedness measures and hazard adjustment, the following responses were examined via questions with yes/no answers regarding having the following items: a torch, a first aid kit, an emergency kit, a transistor radio with spare batteries, a fire extinguisher, a stockpile food and water for three days; or carrying out the following tasks: selecting an emergency contact person living outside the local district, safe storage of hazardous materials and adding lips to shelves to keep things from sliding off. The questions in this section were adopted from Bursa AFAD (2018), Finnis et al. (2010) and Ronan and Johnston (2001).

To examine the importance of earthquake preparedness in children's lives; using the PRISM template, children were asked: "Where would you like to put earthquake hazard to reflect its importance of preparedness?"

\subsubsection{Questionnaire for Previous Exposure to Disaster Education}


317 Education is one of the most important aspects in disaster risk reduction studies. In order to

318 understand the effects of education on children's earthquake risk perception and preparedness, their previous exposure to disaster education was investigated. Children were asked to identify prior exposure to disaster education; in school, outside school, education by the teacher, civil defence, and the year of participation in disaster education on close-ended yes/no questions. The questions in this section were adopted from Finnis et al. (2010) and Ronan and Johnston (2001).

\subsubsection{Questionnaire for Sources of Information Dissemination}

The role of the source of information can be important before, during and after disasters; it can help to develop awareness, prevent future emergencies and reduce their effects, by preparedness, response and recovery (Pan American Health Organization, 2009; Deori \& Baruah, 2014; Reilly \& Atanasova, 2016). A better understanding of children's sources of information is needed for the development of a more effective plan for disseminating risk reduction information, which plays an important role in human safety and reducing losses from hazard events (Zhang et al., 2016). Therefore in this section, we wanted to investigate the importance of the information of sources from children's perceptions, to learn more about children's views and so design better disaster awareness programs for them. In order to understand how important different sources of information were for informing individuals about different hazard types, the children were asked, using the PRISM template, how important for them the following information sources were: their family, school teacher, television and radio, books and the internet.

\subsubsection{The Interview}

The reason for carrying out the interview was to better understand the reasons behind children's responses, and to maximise the strengths of quantitative approach. In this research children were given an opportunity to speak, express their feelings and experiences. As Taylor and Peace (2015) mention: "children are the best authorities on their own lives and more than capable of expressing their views". Speaking directly to children can give us more ideas about how earthquakes affect children's life, we can learn their ideas, thoughts and perceptions. That information can help us to reduce the effects of earthquakes, design better disaster education programs to increase children's earthquake awareness and encourage them to take appropriate actions. To do so, following the questionnaires, separate interviews were carried out with the surveyed children. During their face to face interview, children were asked to explain the 
reasons for their choices when they had used the PRISM template. The interviews of children were conducted by the Turkish-speaking lead researcher, and ethical guidelines were considered carefully.

\subsection{Pilot Study}

In April 2018 a pilot study was conducted in two randomly selected classes of school children, in both Golcuk (Kocaeli) and Ipekyolu (Van), with samples of 38 children, and 28 children questioned respectively. The pilot study aimed to understand whether the survey questions were appropriate, comprehensive, clearly understood, and well defined, as in Hassan et al. (2006). Participants completed all the questions, with all the respondents stating that they did not face any difficulties in understanding the questions. The children completed the questionnaire on a second occasion, and the paired t-test compared the scores between the first and second questionnaires. Paired students' test-retest means for each value were not significantly different. General feedback from the participating children during the pilot study was positive, supporting the selection of the PRISM tool. The participating children commented that using PRISM was easy and that they enjoyed giving their answers using the PRISM template (figure 2). For example some of them said "it is like playing a game" and "very easy to use".

\subsection{Data Analysis}

Using SPSS Statistics 25 software, the Shapiro-Wilk test was applied for verifying the normality of data. The Cronbach's alpha coefficient was reported for measurement scales. Descriptive statistics were used to provide mean values and $95 \%$ confidence intervals of the results. The Pearson correlation was used to measure the relationship between earthquake risk perception, preparedness, and other factors. A chi-square test of independence was performed to examine the relation between cities and the experience of disaster. In every case, a two-tailed p-value $<0.05$ was considered as statistically significant.

Thematic qualitative analysis was preferred to analyse the interview data (Wester, 2005). The reason for selecting thematic analysis was that "rigorous thematic approach can produce an insightful analysis that answers particular research questions' (Braun \& Clarke, 2006). All interviews were recorded and subsequently translated into English for the analysis. The transcripts were read and reread and colour coded manually to identify the key themes. During the analysis Braun \& Clarke, (2006) guidelines were followed because they offer a clear and 
usable framework. The aim of this was to find the kinds of beliefs and explanations that are prevalent among participating schoolchildren as in Knafl et al. (1988) and Taylor \& Peace (2015).

\subsection{Ethical Considerations}

Before conducting the research, the requisite Turkish government approval was obtained. The University of Portsmouth research ethics guidelines were followed as an ongoing and reflexive part of the research process. It should be noted that the researcher carrying out the school surveys (also the first author) has a teaching certificate and experience of working with school children in Turkey.

Children younger than 11 years of age were excluded because of the Turkish Ministry of Education and the University of Portsmouth ethical considerations on the sensitivity of the topic. This study includes children who had earthquake experience thus ethical concerns were our priority as much as the research questions. The children's age group and the sensitivity of the subject matter needed to be considered carefully. The lead researcher's conduct of research was also checked by the school authorities, with the research being well received by the school authorities and with positive comments from the parents of participating children.

\section{RESULTS}

A total of 809 children were surveyed about their perceptions of earthquake risk and their preparedness in Van $(n=384)$ and Kocaeli $(n=425)$. The return rate of the questionnaires was $100 \%$, with $48 \%$ of the school children from Van and $52 \%$ from Kocaeli each agreeing to participate. Of these, 421 were female, and 388 were male. Almost half of all the respondents, $46 \%(n=372)$, reported that they had experienced an earthquake disaster. A chi-square test of independence was performed to examine the relation between cities and the experience of disaster. The relationship between the variables was found to be significant, $X^{2}(1, N=809)=$ 664.16, $p<.01$. Participations from Van (44.6\%) were found more likely than Kocaeli (1.6\%) to have earthquake disaster experience. In addition, the responses from Van and Kocaeli may have reflected socioeconomic differences: in the development ranking statistics of provinces in Turkey, Kocaeli is ranked $4^{\text {th }}$ while Van is $75^{\text {th }}$ (SEGE, 2011).

\section{0}

\subsection{Hazard awareness and Risk Perceptions}

411 Children were asked about the likelihood of occurrence of earthquake hazard in the future, and 412 likelihood of causing injury on a three-point Likert scale. A Shapiro-Wilk test showed a 
413 significant departure from normality W $(809)=.74, \mathrm{p}<.001$. However, Pallant (2013) indicates

414 that this is quite common in large samples. The likelihood of occurrence of earthquake hazard

415 in the future, and likelihood of cause injury responses on a three-point Likert scale has

416 acceptable internal consistency, with a Cronbach alpha coefficient reported of .71, $\mathrm{p}<.001$.

417 (Nunnaly, 1978; Pallant, 2013).

418 As can be seen in Table 1, almost half of the participants rated earthquakes "likely" to occur in 419 the future in their living environment and "likely" to cause injury. However, $21.1 \%$ of the 420 surveyed children in Van, and $21.9 \%$ surveyed children in Kocaeli rated future earthquake 421 occurrences as "unlikely." A total of 48 children from Van and 80 from Kocaeli rated future 422 earthquakes as "unlikely" to cause injury (Table 1).

423423

424 Table 1 Earthquake hazard perceived as likely to occur and likely to cause injury in two 425 Turkish cities of Turkey (\% within cities).

\begin{tabular}{ccccc}
\hline & \multicolumn{2}{c}{ \% likelihood of occurrence } & \multicolumn{2}{c}{ \% likely to cause injury } \\
\hline & $\begin{array}{c}\text { Ipekyolu } \\
\text { (Van) }\end{array}$ & $\begin{array}{c}\text { Golcuk } \\
\text { (Kocaeli) }\end{array}$ & $\begin{array}{c}\text { Ipekyolu } \\
\text { (Van) }\end{array}$ & $\begin{array}{c}\text { Golcuk } \\
\text { (Kocaeli) }\end{array}$ \\
\hline Likely & 56.0 & 48.2 & 66.9 & 60.5 \\
Chance & 22.9 & 29.9 & 20.6 & 20.7 \\
Unlikely & 21.1 & 21.9 & 12.5 & 18.8 \\
\hline
\end{tabular}

426426

427 Table 2 shows the results of children's earthquake awareness. Based on the results, in both 428 surveyed cities, almost half of the participating school children were aware of the earthquake 429 faults, and earthquake risk maps of their home district. Importantly, around $48 \%$ of them 430 reported that they understood those maps.

431431

432 Table 2 Earthquake awareness of children in the two cities examined.

\begin{tabular}{lcccc}
\hline & Ipekyolu (Van) & Golcuk (Kocaeli) \\
\hline \multicolumn{1}{c}{ (\% within cities) "Yes" } & "No" & "Yes" & "No" \\
\hline $\begin{array}{l}\text { Do you know of any active earthquake faults in your home } \\
\text { area? }\end{array}$ & 57.6 & 23.2 & 49.9 & 30.8 \\
$\begin{array}{l}\text { Are you aware of any earthquake risk maps for your home } \\
\text { area? }\end{array}$ & 56.0 & 27.1 & 48.0 & 34.8 \\
\begin{tabular}{l} 
Do you understand those earthquake risk maps? \\
\hline
\end{tabular} & 52.9 & 29.9 & 43.1 & 37.9 \\
\hline
\end{tabular}

433433

434 It is also crucial to understand children's perceptions of natural hazards and whether or not they 435 are related to hazards in their living environments. To explore this, using the PRISM technique, 
Table 3. Mean and standard deviation in $\mathrm{cm}$. of the children's perceptions for risk and 451451

\begin{tabular}{|c|c|c|c|c|c|c|c|}
\hline & & $\begin{array}{c}\begin{array}{c}\text { Range of } \\
\text { scores } \\
(\mathrm{cm})\end{array} \\
\end{array}$ & Earthquake & Flood & Landslide & Wildfire & Storm \\
\hline \multirow{3}{*}{ Risk Perception } & $N$ & & 809 & 809 & 809 & 809 & 809 \\
\hline & Mean & $0-27$ & 6.10 & 8.79 & 10.23 & 10.47 & 9.92 \\
\hline & Std. Deviation & $0-27$ & 4.81 & 5.90 & 6.03 & 6.27 & 6.17 \\
\hline \multirow{2}{*}{$\begin{array}{l}\text { Importance of } \\
\text { Preparedness }\end{array}$} & Mean & $0-27$ & 8.34 & 8.40 & 9.27 & 10.14 & 9.91 \\
\hline & Std. Deviation & $0-27$ & 6.49 & 5.80 & 6.23 & 5.50 & 6.32 \\
\hline
\end{tabular}

452452

\section{4.2. Disaster Preparedness}

\section{$454 \quad$ 4.2.1. Importance of Preparedness}

455 Table 3 shows the PRISM survey results (overall mean and standard deviation) on the 456 importance of disaster preparedness for five hazards (earthquake, flood, landslide, storm, and 457 wildfire). The closer was the distance to the "self" circle that participants placed their response 458 on the PRISM template, the more important it became for them being prepared for a given 459 hazard. Earthquake hazard (mean distance: $8.34 \mathrm{~cm}$ ) and flood hazard (mean distance: 8.40 $460 \mathrm{~cm}$ ) were selected by the children as the ones for which they thought it was most important to 461 be prepared. 
In terms of factual knowledge of earthquake preparedness, children were asked to identify the correct actions for earthquake response, as in Table 4. $63.3 \%(512 / 809)$ of the surveyed children in the two cities were aware of the need to stay inside and take cover in a doorway, under beds or tables. $81.3 \%$ of the school children (658/809) were aware of the need to curl into a turtle shape and protect your head (duck, cover, hold). Unfortunately, $59.5 \%(481 / 809)$ were not aware of the danger from running outside, as the ground is moving, and they could easily be injured or falling by debris. $36.5 \%$ (295/809) were not aware of the danger of "if they are outside, to find a tree, or something sturdy to grab on to" while only $26.5 \%$ (214/809) of the school children considered it best to "stay right where you are and wait for it to be over".

Table 4 Children's awareness of correct actions in response to earthquakes (correct responses are in light grey).

\begin{tabular}{lccc}
\hline & Ipekyolu (Van) & Golcuk (Kocaeli) \\
& (\% within city) & $N=384$ & $N=425$ \\
\hline Stay inside and take cover in a doorway, under beds or tables & 57.3 & 68.7 \\
Curl into a turtle shape and protect your head (duck, cover, hold) & 78.6 & 83.8 \\
If you are outside, find a tree or something sturdy to grab on to & 39.6 & 33.6 \\
Stay right where you are and wait for it to be over & 36.7 & 17.2 \\
Run outside & 65.6 & 53.7 \\
\hline
\end{tabular}

474474

475

476

477

478

479

480

481

482

483

484484

485

\subsubsection{Physical preparedness}

Table 5 shows that almost half of the children (171/384) in Van reported that they had a family emergency plan. However, in Kocaeli, only 29.2\% (124/425) of the children reported that they had a family emergency plan. While more than half of the children $(51.8 \%)$ in Kocaeli practiced what to do in case of an emergency at school, only $22.4 \%$ of children practiced what to do in case of an emergency at the sampled school in Van province. Only $7.6 \%$ (62/809) of the children practiced what to do in case of an emergency at home in the two provinces. In both cities, under $41 \%$ of school children reported knowledge of knowing exits, assembly areas, utility switches, and where to meet or leave a message in an emergency.

Table 5 Information on preparedness plans and practices

\begin{tabular}{|c|c|c|c|}
\hline & & Ipekyolu (Van) & Golcuk (Kocaeli) \\
\hline & (\% within city) & $N=384$ & $N=425$ \\
\hline I have family emergency plan & & 44.5 & 29.2 \\
\hline I have practiced what to do in case of emergency at school & & 22.4 & 51.8 \\
\hline
\end{tabular}


I have practiced what to do in case of emergency at home

I know exits, assembly areas, utility switches

I know where to meet or leave a message in an emergency

487 In order to understand children preparedness measures and hazard adjustment adoptions, 488 several questions were asked (as shown in Table 6). It can be seen in the table that less than 489 half of the participated school children reported having key items, such as first aid kit, radio 490 with spare battery, a torch, an emergency kit, pick an emergency contact person outside of their 491 area, fire extinguisher, and stockpile of water and food for three days. Earthquake hazard 492 adjustments, such as storing hazardous materials safely are adopted by $36.3 \%$ (294/809) of the 493 children, and adding lips to shelves to keep things sliding off are adopted by $41 \%$ (332/809) 494 in total.

496 Table 6 Preparedness measures and hazard adjustment

\begin{tabular}{|c|c|c|}
\hline & \multicolumn{2}{|c|}{ Ipekyolu (Van) Golcuk (Kocaeli) } \\
\hline (\% within city) & $N=384$ & $N=425$ \\
\hline I have a first aid kit & 32.3 & 42.6 \\
\hline I have a radio with a spare battery & 29.4 & 40.2 \\
\hline I have a torch & 41.4 & 39.1 \\
\hline I have a stockpile of water and food for three days & 32 & 44.9 \\
\hline I picked an emergency contact person outside my area & 10.4 & 4.9 \\
\hline I have an emergency kit & 36.5 & 29.4 \\
\hline I store hazardous materials safely & 32 & 40.2 \\
\hline I add lips to shelves to keep things sliding off & 44.8 & 37.6 \\
\hline I have a fire extinguisher & 37 & 37.4 \\
\hline
\end{tabular}

497497

498

499

500

501

502

503

504

505

\subsection{Previous exposure to disaster education}

Results of previous exposure to disaster education shown in Table 7 indicate that nearly half of the participants (383/809) from both cities participated in disaster education at school, and a minority of them participated outside of the school (5.2\% or less). Between $32 \%$ and $44 \%$ of the surveyed children participated in disaster education in 2017, significantly more than in 2016 (between 5\% and 11\% for Van and Kocaeli respectively). In Van province disaster education was mostly via school teachers; however in Kocaeli province the civil defence seems to be more active. 
507 Table 7. The school children's participation in earthquake education programmes.

\begin{tabular}{|c|c|c|}
\hline (\% within city) & $\begin{array}{c}\text { Ipekyolu (Van) } \\
N=384\end{array}$ & $\begin{array}{c}\text { Golcuk (Kocaeli) } \\
N=425\end{array}$ \\
\hline In School & 43 & 51.3 \\
\hline Outside School & 2.3 & 5.2 \\
\hline By teacher & 37.2 & 32 \\
\hline By civil defence & 8.6 & 22.4 \\
\hline Participated in 2018 & 5.2 & 6.8 \\
\hline Participated in 2017 & 32.6 & 44.0 \\
\hline Participated in 2016 & 5.5 & 10.8 \\
\hline Participated in before 2016 & 1.8 & 6.8 \\
\hline
\end{tabular}

508508

\section{4.4. Sources of information dissemination}

510 Using the PRISM technique, the children were asked about the importance of the information

511 provided by the sources for learning about local natural hazards. The closer the distance was

512 to the "self" circle that participants placed their response cross on the PRISM template, the

513 more they thought a given information source was important in their life. Table 8 shows the

514 mean and standard deviation of the PRISM $(0-27 \mathrm{~cm})$ responses: the information sources being

515 family, school teacher, television and radio, book, or the internet. The results show that children

516 in the Kocaeli and Van cities examined had "family" as their first source (means 4.87 and 4.68,

517 respectively) of information about hazards. "Internet" (mean 8.53) was selected as a second

518 source of information in Kocaeli, while "school teacher" (mean 7.78) was selected as a second 519 source of information in Van.

520520

521 Table 8. The importance of the information of sources from children's perceptions.

522

\begin{tabular}{llllllll}
\hline \multirow{2}{*}{ Kocation } & Variable & Range & Family & $\begin{array}{l}\text { School } \\
\text { Teacher }\end{array}$ & Tv \& radio & Book & Internet \\
& $N$ & & 425 & 425 & 425 & 425 & 425 \\
& Mean & $0-27$ & 4.87 & 9.53 & 10.18 & 11.16 & 8.53 \\
\multirow{2}{*}{ Van } & Std. Deviation & $0-27$ & 4.10 & 7.56 & 7.45 & 7.40 & 6.85 \\
& $N$ & & 384 & 384 & 384 & 384 & 384 \\
& Mean & $0-27$ & 4.68 & 7.78 & 9.77 & 9.27 & 8.08 \\
& Std. Deviation & $0-27$ & 3.71 & 6.35 & 6.72 & 6.80 & 6.21 \\
\hline
\end{tabular}


4.5. Relationship between earthquake risk perception, preparedness, and other factors

525 In this section we examine the correlation between earthquake risk perception and other factors

526 (e.g. perceived importance of preparedness, likelihood of earthquake occurrence and cause

527 injury, earthquake education. See Table 9). This is done by observing the correlation

528 coefficient, $r$, and its respective level of marginal significance, $p$, for the number of cases, $n$.

529 Table 9 shows the relationship of the variables.

530530

531 Table 9. Correlation coefficient (Pearson r) matrix for variables.

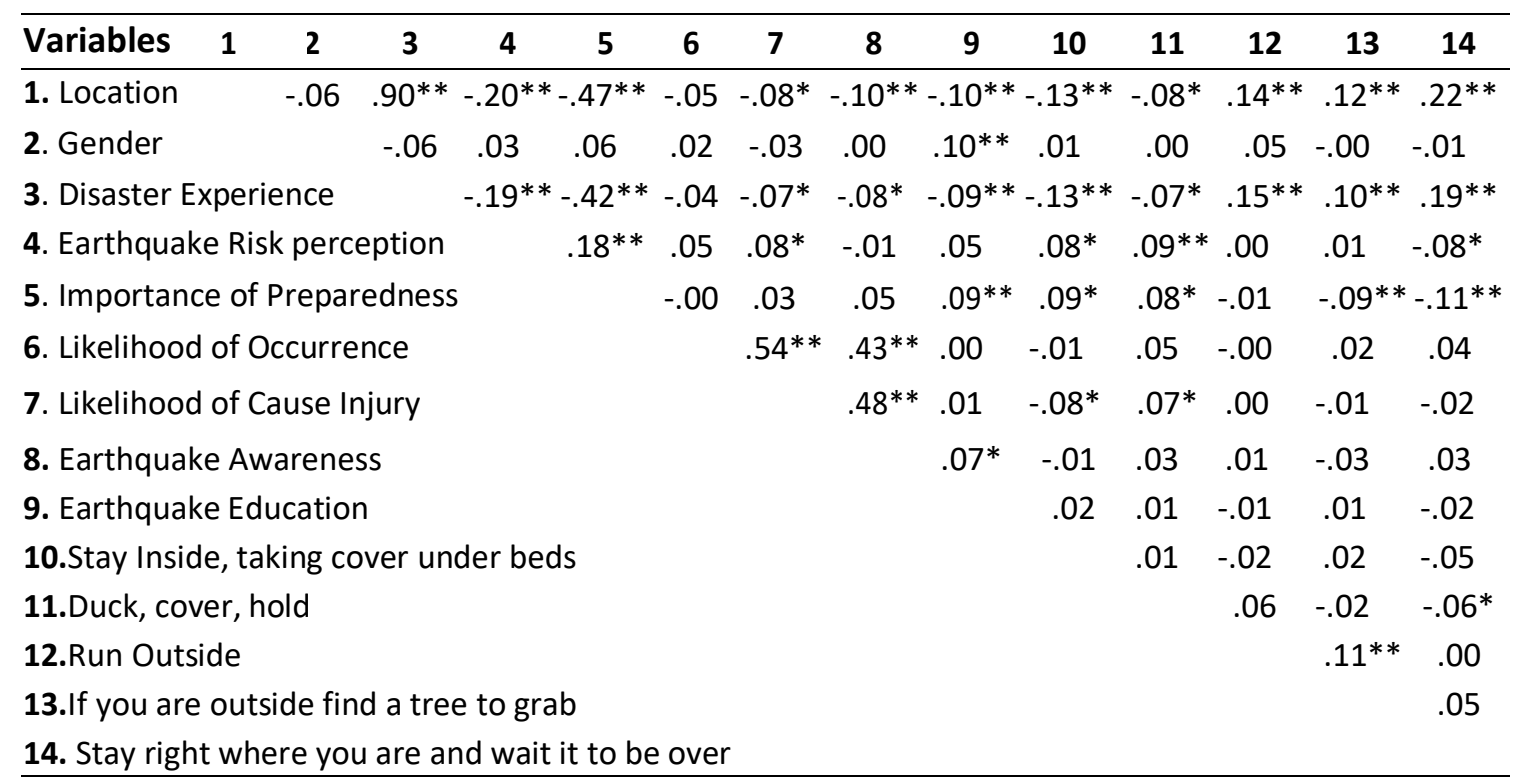

* Correlation is significant at the 0.05 level (2-tailed)

** Correlation is significant at the 0.01 level (2-tailed).

532532

533

534

535

536

537

538

539

540

541

542

543

\subsubsection{Risk Perception and Factual Knowledge}

The results indicate that earthquake risk perception is related to the knowledge of correct actions of earthquake preparedness. There was a significant correlation between earthquake risk perception related to "stay inside and take cover in a doorway, under beds or tables" ( $\mathrm{r}=$ $.08 ; \mathrm{n}=809 ; \mathrm{p}<.05)$, and "curl into a turtle shape and protect your head (duck, cover, hold)" $(\mathrm{r}=.09, \mathrm{n}=809, \mathrm{p}<.01)$. That indicates that children with higher levels of earthquake risk perception also had awareness of the correct earthquake preparedness actions. There is a significant negative correlation between children's earthquake risk perception and "stay right where you are and wait for it to be over" $(\mathrm{r}=-.08, \mathrm{n}=809, \mathrm{p}<.05)$; i.e., children who have low perception of earthquake risk are more likely to prefer to stay where they are and wait for it to be over. Although the correlations are significant between these variables, they remain 
rather weak. Therefore, they do not represent large differences. The relation between earthquake risk perception and; "run outside" $(\mathrm{r}=.00)$, and "if you are outside, find a tree or something sturdy to grab on to" $(\mathrm{r}=.01)$, was weak and did not reach statistical significance. There is no significant relationship between earthquake risk perception and "run outside," and "if you are outside, find a tree or something sturdy to grab on to."

\subsubsection{Factual knowledge and importance of preparedness}

The results indicate that responses of perceived importance of earthquake preparedness were strongly related to correct responses of earthquake preparedness knowledge, "stay inside and take cover in a doorway, under beds or tables" $(\mathrm{r}=.09, \mathrm{n}=809, \mathrm{p}<.05)$, "curl into a turtle shape and protect your head (duck, cover, hold)" $(\mathrm{r}=.08, \mathrm{n}=809, \mathrm{p}<.05)$. These mean that children who placed higher levels of importance on preparedness also made correct responses regarding earthquake preparedness actions. There was also a significant negative correlation between the importance of preparedness and "stay right where you are and wait for it to be over" $(\mathrm{r}=-.11, \mathrm{n}=809, \mathrm{p}<.01)$, and "if you are outside, find a tree or something sturdy to grab on to" $(\mathrm{r}=-.09, \mathrm{n}=809, \mathrm{p}<.01)$. That indicates that the higher the importance of preparedness, the higher were the correct responses on knowledge of earthquake preparedness knowledge. Findings in this section show that correlations between the variables mentioned were significant; however, the relationships are quite weak. In addition, the one exception that did not relate to the psychological issue of the importance of preparedness was: "run outside" $(r=-.01)$. This relationship was weak and did not reach statistical significance.

\subsubsection{Location, risk perception, awareness, education and other variables}

The results show that location was strongly related to many variables: disaster experience ( $\mathrm{r}=$ $.90)$, earthquake risk perception of children $(r=-.20)$, and importance of preparedness $(r=-$ $.47)$, likelihood of cause injury $(\mathrm{r}=-.08)$, earthquake awareness $(\mathrm{r}=-.10)$, earthquake education $(\mathrm{r}=-.10)$, and the knowledge of correct actions of earthquake preparedness actions (as shown Table 9).

Previous exposure to earthquake education was strongly related to the earthquake awareness of children $(\mathrm{r}=.07, \mathrm{n}=809, \mathrm{p}<.05)$. It is reassuring to find that children who have previous earthquake education have higher earthquake awareness. Disaster education is also strongly related to the psychological issue of the importance of preparedness $(r=.09, n=809, p<.01)$. That indicates that children have higher levels of perceived importance of preparedness when they have received earthquake education. Furthermore, the earthquake awareness of children 
578 was strongly related to the likelihood of future earthquake occurrence $(\mathrm{r}=.43, \mathrm{n}=809, \mathrm{p}<$ $579.01)$, and cause of injury $(\mathrm{r}=.48, \mathrm{n}=809, \mathrm{p}<.01)$. These indicate that children who have

580 previous disaster education are more likely to foresee future earthquake occurrence and the 581 potential causes of injury.

582 The findings also indicate that gender did not relate to either children's perceptions of risk or 583 the importance of preparedness. However, it is important to point out that even if findings 584 showed significant correlations, the $\mathrm{r}$ values suggested a small size effect.

\section{5}

586

587

588

589

590

591

592

593

594

595595

\subsection{Interview Results}

The interview results show that the children mainly discussed four themes; education, family, earthquake-safe buildings, and beliefs (as shown in Table 10). Firstly, the most highlighted theme from the interview analysis was "education". In total 68 of the children out of 100 , directly or indirectly mentioned the "education" theme. It appears that activities offered by schools can affect children's views, attitudes, and knowledge of disasters. The following are some examples. "I do not scare much about earthquake hazards because we practice it in our school every year; therefore, I feel ready" (Umut, male, Golcuk). "It is really important for me to be prepared for an earthquake because our teacher told us in the class, we are living in a high earthquake risk area." (Rabia, female, Ipekyolu).

Table 10. Results of the qualitative research

\begin{tabular}{|c|c|c|}
\hline Theme & Categories & Sample of quotation \\
\hline \multirow{3}{*}{ Education } & $\begin{array}{l}\text { Lack of plan and } \\
\text { practice }\end{array}$ & $\begin{array}{c}\text { We live in a high seismic earthquake zone, and I } \\
\text { think I do not know enough how to protect myself. } \\
\text { We do not practice enough emergencies to cope } \\
\text { with a real earthquake event. }\end{array}$ \\
\hline & $\begin{array}{l}\text { Lack of } \\
\text { earthquake } \\
\text { information } \\
\text { Lack of awareness }\end{array}$ & $\begin{array}{l}\text { I do not believe so; my teacher mentioned much } \\
\text { about earthquake preparedness. } \\
\text { I cannot find much information about earthquakes } \\
\text { in school books. }\end{array}$ \\
\hline & & I do not think that earthquakes are a serious event. \\
\hline \multirow[b]{2}{*}{ Family } & & $\begin{array}{c}\text { My family does not see earthquakes as a significant } \\
\text { hazard. }\end{array}$ \\
\hline & $\begin{array}{l}\text { Understanding } \\
\text { the importance of } \\
\text { the family role }\end{array}$ & $\begin{array}{l}\text { My family does not secure furniture and dangerous } \\
\text { things that can harm or injure us during or after an } \\
\text { earthquake. } \\
\text { I do not want to lose my family because of } \\
\text { earthquakes. }\end{array}$ \\
\hline
\end{tabular}


We do not talk much about earthquakes and earthquakes preparedness at home.

\section{I do not trust buildings because I do not think they design for earthquakes. \\ Earthquake safe buildings \\ Insufficient trust \\ in buildings \\ I lost one of my family members due to the bad design of the buildings. \\ I do not believe that my building is strong enough to resist earthquake shakes; it makes me anxious. \\ God knows when we live or when we die, preparation is not needed. \\ Beliefs \\ Religious beliefs \\ Risk belief \\ We cannot predict an earthquake, so preparation is not essential for me to \\ I do not think earthquakes will impact my family or me because our preparation is good enough to protect us.}

Earthquakes are not serious situations.

597597

598598

599 The "family" theme was the second key finding from the interview data analysis. The 600 importance of family preparation at home was highlighted. The children's responses show that 601 their initiatives were not enough to take precautionary actions without their families' help. 602 Also, a desire to protect their families from the consequences of earthquake disaster appears to 603 drive children to be better prepared for earthquakes. For example, "earthquakes bother me a lot 604 because it can give harm to my family" (Eyyub, male, from Golcuk); or, "I feel afraid to lose 605 my family because of the earthquakes, so preparation is really important for me" (Sukran, 606 female, Golcuk); and, "I know that it is very important to be prepared for earthquakes, but how 607 can I stabilize the furniture at the home by myself. I think my family's preparation is more 608 important than my preparation" (Reyhan, female, Ipekyolu).

609

610 The interview results show that the construction of children's homes influences their 611 earthquake risk perception and their preparedness. They highlight the importance of 612 earthquake-safe buildings and structures; for instance: "earthquakes really bother me because 613 I do not believe that my home is strong enough to resist earthquake shake" (Yakup, male, 
614 Golcuk), "no matter how much individual preparation I make, if my home or school structures 615 are not strong enough to protect me, I might lose my life" (Asaf, male, Ipekyolu).

616

617 Another key theme found in the interview analysis is the religious belief of the children. The 618 religious belief of children seems to shape their earthquake risk perception and preparedness. 619 Several individual responses (15 interviews in total) referred to God to explain the reason for 620 their earthquake risk perception and preparedness. For example, "earthquakes depend on God, 621 we cannot do much about it" (Ahmet, male, Golcuk), "the only thing I can do to protect myself 622 from earthquakes is praying God" (Elif, female, Ipekyolu). Children's beliefs about earthquake 623 risk also shape their risk perception and preparedness. For example, "Earthquakes cannot be 624 predictable, we do not know when it will happen, so how can I be ready all the time" (Fatih, 625 male, Golcuk). "I do not believe earthquakes are a serious situation, because I have made my 626 preparation for it" (Sevgi, female, Ipekyolu).

627

\section{4.6.1. Linking interview results to quantitative results}

629 Mixed methods research is a creative and expansive form of research, using multiple 630 approaches to answer research questions, rather than restricting the researcher's choice 631 (Johnson \& Onwuegbuzie, 2004). Our findings from the qualitative data show a consistent 632 relationship with the findings from quantitative data and help to explain some of the underlying 633 factors (such as the ones in Table 10). For example, the children pointed to a lack of plans and 634 practice, earthquake information and awareness, when they were asked to explain the reason 635 for their choices on the PRISM template for earthquake risk perception and preparedness, 636 relative to the results found in the quantitative data. Furthermore, the qualitative data findings 637 explain other important points that affect children's earthquake risk perception, as well as 638 importance of earthquake preparedness which could not be obtained in the qualitative data, 639 such as: importance of school education for earthquakes, importance of family earthquake 640 awareness and preparation, fears and beliefs, importance of earthquake safe building.

641

642 5. Discussion

\section{$643 \quad$ 5.1. Risk perceptions}

644 The findings of this research show that children perceive earthquake hazards as being more 645 threatening than floods, landslides, wildfires, and storm events (Table 3). In both of the 646 sampled cities, children rated the earthquake hazard as likely to occur and likely to cause injury 
647 in the future (Table 1). Also, they reported that the majority of them are aware of earthquake 648 fault lines in their district (Table 2). The children's responses seem to reflect their local 649 environment being in areas with high earthquake risk. AFAD (2018b) notes that earthquakes 650 are frequently occurring in both cities. Our research findings indicate that children were able 651 to identify the earthquake risk in their environment (Table 1, 2, 3).

652 Our research findings also indicate that home location is related to children's earthquake risk 653 perception $(\mathrm{r}=-.20, \mathrm{n}=809, \mathrm{p}<.001)$ and children's earthquake awareness $(\mathrm{r}=-.10, \mathrm{n}=809$, $654 \mathrm{p}<.004)$. Children who lived in an area with lower socioeconomic status had a lower 655 perception of earthquake risk. However, this might be due to other factors beyond the 656 socioeconomic status of children in Kocaeli and Van children; therefore, further research is 657 needed into the relationship between the socioeconomic status of children and their perception 658 of earthquake risk.

659 Previous exposure to education appears to play a role in children's earthquake risk perception 660 and their level of reported earthquake awareness. Almost half of the children reported that they 661 were aware of the earthquake faults in their living environment; however, it is a cause for 662 concern that $30 \%$ or less of the children were not aware of their local earthquake risk (Table 663 2). The results indicate that children who had previous earthquake education were more aware 664 of their earthquake risk than those who have not had an earthquake education. This clearly 665 indicates that earthquake education programs should be increased, especially in areas prone to 666 earthquakes. The interview data collected in this study also points to the importance of 667 education for improving earthquake risk awareness, with the results showing that most of the 668 children linked their earthquake risk perception to a lack of earthquake information.

669 In terms of previous exposure to earthquake disaster, the results seem to be related to the 670 children's risk perception $(r=-.19, \mathrm{n}=809, \mathrm{p}<.001)$, and their level of awareness $(\mathrm{r}=-.08, \mathrm{n}$ $671=809, \mathrm{p}<.013)$. Having experience of earthquakes in the past has an effect on children's 672 earthquake risk perception and their awareness.

673 Previous research shows some similar findings to the results of this study. For example, 674 working with 10-11 years old children in Japan, Yasuda et al. (2018) showed that children who 675 experienced a disaster in the past have a higher awareness of threats and prevention; however, 676 this effect was short-lived. A study carried out with children in Christchurch, New Zealand, 677 indicated that they were able to identify the flood risk in their living environment (Finnis et al., 678 2004). 
679 Some researchers have indicated that higher income levels have a positive impact on levels of 680 preparedness, due to a rise in public risk perception (Turner et al., 1986; Bradford et al., 2012; $681 \mathrm{Hal}$ et al., 2016). Lamson (1983) suggested that people of lower socioeconomic status are more 682 likely to have hazardous or risky occupations, and they thus might employ coping mechanisms 683 to deal with it. It is important to point out that our research is based on child participation rather 684 than adult. Thus this makes the findings difficult to compare to adult-based research. However 685 the findings of this research, in line with adult based findings, the children who live in an area 686 with lower socioeconomic status have a lower perception of earthquake risk. Also, research 687 carried out in Mexico with children shows that urban children are more aware of the 688 preparedness activities toward earthquakes than children living in semi-rural areas (Santos689 Reyes et al., 2017).

690 In our research, we have found that previous exposure to education has an important role in 691 children's earthquake awareness. Research with high school students in Japan also indicates 692 that education can help participants to be more aware of earthquakes (Shaw et al., 2004). 693 Similar results can be found in Santos- Reyes et al. (2017), Finnis et al. (2010), and Yasuda et 694 al. (2018).

\section{5.2. Preparedness}

696 In terms of psychological issue of the importance of preparedness, the surveyed children 697 selected earthquakes (mean 8.34) and floods (mean 8.40) as the most important hazard to be 698 prepared for relative to landslides, storms and wildfire hazard (Table 3). The children's sense 699 of importance of preparedness is related to their previous earthquake experience $(r=-.42$, $700 \mathrm{n}=809, \mathrm{p}<.001)$, disaster education $(\mathrm{r}=.09, \mathrm{n}=809, \mathrm{p}<.001)$, earthquake risk perception $701(\mathrm{r}=.18, \mathrm{n}=809, \mathrm{p}<.001)$, and location $(\mathrm{r}=-.47, \mathrm{n}=809, \mathrm{p}<.001)($ Table 9).

702 Regarding the physical preparedness of children, preparedness via an emergency plan and 703 practice drills had a low rating $(44.5 \%$ or less in Table 5$)$. It is interesting that although the 704 majority of the children reported that they were aware of their local earthquake risk, their actual 705 preparedness on plan and practice was poor, with more than half of the participants reporting 706 that they did not have an emergency plan, and they did not practise earthquake drills. From the 707 children's responses, family emergency plans appear to be more common in Van than in 708 Kocaeli. This might be related to the disaster experience of people living in Van, the majority 709 of them have experienced the 2011 Van earthquake. This bitter disaster experience might have 710 encouraged the families to have "family emergency plan" to better prepare for future 
711 earthquakes. On the other hand, in Kocaeli, children practiced earthquake drills in their school 712 more than the Van children. Although all the participating schools are government-run and 713 have the same school curriculum, there is no government obligation to practice earthquake 714 drills at schools. Also, in both participating provinces, only a minority of the children have 715 practiced what to do at home in case of a major emergency (8.9\% or less in Table 5). When we 716 look at the results for the sources of information dissemination, the surveyed children preferred 717 their families as the main source of information for learning about natural hazards. Thus 718 children's engagement with their families, and practising what to do at home in the case of a 719 major emergency, them to better prepare to cope with earthquake disasters. Furthermore, 720 earthquake education programs should include showing children the locations of: exits, 721 assembly areas, and utility switches, as well as where to meet or leave a message in an 722 emergency - more than half of the participants reported that they were aware of those crucial 723 emergency response features.

724 In terms of earthquake preparedness measures and hazard adjustments, participating children 725 in both cities reported that $44.9 \%$ or less of them have preparedness measurements and hazard 726 adjustments (Table 6). Even the study locations prone to high earthquake risk, it was surprising 727 to see that children's hazard adjustments for earthquakes were low (below 45\%, Table 6). 728 Children's preparedness levels can be increased via effective earthquake education programs. 729 To do so, school authorities should have more responsibility to encourage children and their 730 families to take more preparedness measures - not including children's families in this process 731 can severely limit earthquake emergency preparedness programs. Children's easily-applied 732 risk reduction actions for earthquakes, such as fitting lips on shelves to keep things from sliding 733 off, or storing hazardous materials safely, show that children are capable of taking some 734 measures to protect themselves and their families. Some of the interview results (as shown in 735 Table 10) indicate that children want to make hazard adjustments in their homes to reduce the 736 potential risks, but without their families support they are not able to do so. Thus it is not just 737 children's education, but also family education, that has an important role in earthquake 738 preparedness.

739 In this research, we also have examined the effects of gender on the psychological issues of 740 children's earthquake risk and preparedness levels. The results show that gender is not a major 741 factor associated with children's perceptions of earthquake risk and preparedness. Based on 742 analyses of previous adult-based research, women tend to perceive environmental and safety 743 risks higher than men (Hitchcock, 2001). In adult-based research, Armas (2006) found that 
744 females had a higher earthquake risk than males in Bucharest, Romania. Furthermore, in a child 745 sample study in Indonesia, girls' risk perception of landslide hazard was found to be higher 746 than that of boys, while the flood risk perception of boys was higher than that of girls (Haynes 747 et al., 2010).

748 Taken together, education is an essential issue to mitigate the impacts of earthquake disasters, 749 consequently, the authors of this article are in agreement with the findings of Graham et al. 750 (2006), Mutch (2014) and Torani et al. (2019). Schools are clearly vitally important places for 751 education, and they can play a key role in gaining disaster awareness and preparedness (Mutch, 752 2014). Furthermore, schools play an important part in community life, as places of daily mass 753 gathering and have a key role in disaster management (Graham et al., 2006). The results of this 754 study support the findings of Proctor et al. (2007) and Repetti et al. (2002), that the family has 755 been linked to wide-ranging child outcomes in the social context of the child. Also our findings 756 are in line with Najafi et al. (2018) who argued that feelings, emotions, and social norms are 757 likely to influence beliefs.

\section{5.3. Limitations}

759 This study has some limitations. The sample selected for this study is limited to school children 760 living in Van and Kocaeli provinces of Turkey; therefore, the findings cannot be generalised 761 to all children. Another limitation could be that selection bias exists in the data. Although the 762 lead researcher and Ministry of National Education representatives in two cities were careful 763 to select a representative sample of the socioeconomic background of the surveyed schools, 764 there is a possibility that children from participating schools may not be generalizable to the 765 population of the provinces of Van and Kocaeli, or indeed the entire population of Turkey. 766 Nevertheless, the results provide useful insights into children's earthquake perception, 767 awareness, and preparedness. Another concern is the reliability of the responses from the 768 surveyed children. Although the children were asked about any aspects of the survey that they 769 found difficult, it might be that the children answered the questions with minimal thinking, or 770 they might have copied answers from a classmate. Finally, the PRISM technique was initially 771 designed as a clinical psychology methodology for assessing the treatment of an illness, not for 772 the perception of earthquake risk and the importance of earthquake preparedness. However, 773 PRISM - being a non-verbal and easy to use, pictorial technique - was found to be appropriate 774 and very useful in our study.

\section{5 \\ 6. Conclusions}


776 The paper has presented the results of earthquake awareness, risk perception, and levels of 777 preparedness among children in two provinces of Turkey with major earthquake risks: Van and 778 Kocaeli. The findings show that $21.1 \%$ of the participating children in Ipekyolu (Van) and $77921.9 \%$ of the participating schoolchildren in Golcuk (Kocaeli) think that the likelihood of 780 occurrence of a future earthquake in their living environment is "unlikely" (Table 1). 23.2\% of 781 the children participating in Ipekyolu (Van), and $30.8 \%$ in Golcuk (Kocaeli) reported that they 782 were not aware of any earthquake faults in their living area (Table 2).

783 The results of this research indicate that the surveyed children have accurate earthquake risk 784 perceptions since more than half of the participants are aware of the likelihood of the future 785 earthquake occurrence and its consequences. More than half of the participants in two cities 786 were aware of the correct actions knowledge for earthquakes (Table 4). However, regarding 787 children's preparedness, more than half of the participants in the two cities do not have enough 788 information on preparedness plans and practices, nor on preparedness measures and hazard 789 adjustment (Table 5 and 6).

790 The findings of this study highlight the importance of earthquake education programmes to 791 increase children's levels of earthquake awareness and their coping mechanisms, as well as 792 encouraging children to take measures to protect themselves and their families. The children 793 who participated in the earthquake education programme had higher earthquake awareness, 794 and predicted the future earthquake occurrence and the potential causes of injury. Our results 795 show that children in the two examined cities have "family" as their first source to get 796 information about hazards, with our results from qualitative surveys giving supporting 797 arguments. The findings show a consistent relationship between earthquake risk perception, 798 earthquake awareness, factual knowledge of preparedness, the importance of preparedness, and 799 earthquake education programs. Children who lived in an area of lower socioeconomic status 800 had a lower perception of earthquake risk. Also, our results show that gender was not a major 801 factor associated with children's perceptions of earthquake risk and preparedness.

802 The study has some important implications, both theoretically and empirically, as well as for 803 disaster risk reduction applications. While this paper was under the review process, the Elazig 804 (Turkey) earthquake (6.8 $\left.M_{w}\right)$ occurred in January 2020: it killed 41 people, injuring and 805 displacing a considerable number of people, who now face a long and hard fight to return to 806 their normal life. The effects of this earthquake were devastating for the people who live in 807 Elazig and Malatya cities, especially for the children. As the risks from earthquakes in Turkey 
809 children perceive earthquake risks, to more effectively assist them to prepare for, and to cope 810 with, earthquakes. Within the disaster risk reduction sector, we have provided perception 811 insights that can improve the communication and dissemination of information on earthquake 812 hazards. Consequently, the findings of this study are important to understand children's 813 earthquake risk perceptions and their preparedness, informing the development of disaster risk 814 reduction strategies, not just in Turkey but also in other countries prone to earthquakes.

\section{6.1. Recommendations}

816 This study used the PRISM technique to measure children's perceptions of earthquake risk and 817 preparedness. The PRISM technique is recommended for other risk perception studies: the 818 surveyed children found it easy to use, with its visual simplicity and interactive features. A 819 further recommendation is to carry out longitudinal research into children's earthquake risk 820 perceptions, to examine the effectiveness of educational interventions for disaster risk 821 reduction, e.g., disaster preparedness publicity campaigns, inclusion of disaster topics in 822 science and/or geography curriculum of schools, including school-hosted events for building 823 local maps of hazardous terrain or vulnerable features. Further research is also needed into the 824 relationship between the socioeconomic status of children and their perception of earthquake 825 risks.

826 In terms of policy and practice, disaster education programs should be strengthened, with 827 frequent school emergency practices: drills can improve children's coping levels during 828 hazardous events, such as earthquakes. Hazard maps, highlighting high-risk areas, should be 829 readily available and easy to understand for children to better prepare for a potential emergency 830 event in their local area. Disaster education programs should include the training of teachers to 831 work with children to understand, or even co-create, maps of their local hazards and high-risk 832 areas, with a discussion about ways of reducing hazard impacts and improving community 833 resilience. This study thus supports the recommendation of Anderson (2005): recognizing 834 children's capabilities and vulnerabilities should be policy and research priorities for disaster 835 risk reduction.

\section{Acknowledgements}

837 This paper is based on a Ph.D. research project of the first author/lead researcher, funded by the Turkish Ministry of National Education. The authors wish to thank the managers of the 
852 Amadeo, K. (2019). "How the 2011 Earthquake in Japan Affected the Global Economy". The

859 Becker, J. S., Paton, D., Johnston, D. M., Ronan, K. R., \& McClure, J. (2017). The role of prior 860 861

862

865 Bodoque, J. M., Díez-Herrero, A., Amérigo, M., García, J. A., \& Olcina, J. (2019). Enhancing 866 flash flood risk perception and awareness of mitigation actions through risk 867

868 Bradford, R. A., O'sullivan, J. J., Van der Craats, I. M., Krywkow, J., Rotko, P., Aaltonen, J., 869

participating schools and the children who so kindly participated in the data collection. We also would like to warmly thank the anonymous reviewers whose comments strengthened the paper.

\section{References}

AFAD, (2013). The Disaster and Emergency Management Presidency of Turkey. "Schools disaster awareness and education project". Ankara.

AFAD, (2014). The Disaster and Emergency Management Presidency of Turkey. "Mudahale,

AFAD, (2018a). The Disaster and Emergency Management Presidency of Turkey. "Disaster Management and Natural Disaster Statistics in Turkey". Retrieved from 848 https://www.afad.gov.tr/upload/Node/35429/xfiles/Turkiye_de_Afetler.pdf

AFAD, (2018b). An Interactive Web Application Prepared For Earthquake Hazard Maps of Turkey - Turkey Prime Ministry Disaster \& Emergency Management Authority https://tdth.afad.gov.tr/, Ankara, Turkey. (in Turkish)

Balance. Retrieved from https://www.thebalance.com/japan-s-2011-earthquaketsunami-and-nuclear-disaster-3305662

Anderson, W. A. (2005). Bringing children into focus on the social science disaster research agenda. International Journal of Mass Emergencies and Disasters, 23(3), 159.

Armaş, I. (2006). Earthquake risk perception in Bucharest, Romania. Risk Analysis, 26(5), 1223-1234. experience in informing and motivating earthquake preparedness. International journal of disaster risk reduction, 22, 179-193.

Becker, J., Paton, D., Johnston, D., \& Ronan, K. (2014). Societal Influences on Earthquake Information Meaning-Making and Household Preparedness. International Journal of Mass Emergencies \& Disasters, 32(2). communication: A pre-post survey design. Journal of Hydrology, 568, 769-779. ... \& Schelfaut, K. (2012). Risk perception-issues for flood management in Europe. Natural hazards and earth system sciences, 12(7), 2299-2309.

Braun, V., \& Clarke, V. (2006). Using thematic analysis in psychology. Qualitative research in psychology, 3(2), 77-101.

Britten, N. (1995). Qualitative research: qualitative interviews in medical research. Bmj, 311(6999), 251-253.

Bryman, A (2012). Social Research Methods, $4^{\text {th }}$ edn, Oxford University Press, UK. 
876 Büchi, S., \& Sensky, T. (1999). PRISM: Pictorial Representation of Illness and Self Measure:

877

878

879 Büchi, S., Buddeberg, C., Klaghofer, R., Russi, E. W., Brändli, O., Schlösser, C., \& Sensky,

880

881

882

883 Büchi, S., Sensky, T., Sharpe, L., \& Timberlake, N. (1998). Graphic representation of illness:

884

885

886

887

888

889

890

891

892

893

895

896

897

898

899

900

901

902

903 Dwyer, A., Zoppou, C., Nielsen, O., Day, S., \& Roberts, S. (2004). Quantifying social 904

905

906

907

908

909

910

911

912 Erdik, M., Aydinoglu, N., Fahjan, Y., Sesetyan, K., Demircioglu, M., Siyahi, B., ... \& 913

914

T. (2002). Preliminary validation of PRISM (Pictorial Representation of Illness and Self Measure)-A brief method to assess suffering. Psychotherapy and Psychosomatics, 71(6), 333-341.

a novel method of measuring patients' perceptions of the impact of illness. Psychotherapy and Psychosomatics, 67(4-5), 222-225.

Bursa AFAD (2018). Bireyler ve aileler icin afet bilinci egitimi, Egitim Bilgi Formu. Ankara. Form A.

Çetin KÖ, Bakır S, Ulusay R, Gülkan P. (2003). TDV/DR 014-86 May 1, 2003 Bingol

Earthquake examination Report. Istanbul: Turkish Earthquake Foundation.

Creswell, J. W., \& Clark, V. L. P. (2017). Designing and conducting mixed methods research. Sage publications.

Cvetković, V., Roder, G., Öcal, A., Filipović, M., Janković, B., \& Noji, E. (2018). Knowledge of children and youth about forest fires: Discrepancies between basic perception and 894 reality. Vojno delo, 70(1), 171-185.

De Pascale, F., Bernardo, M., Muto, F., Di Matteo, D., \& Dattilo, V. (2017). Resilience and seismic risk perception at school: a geoethical experiment in Aiello Calabro, southern Italy. Natural Hazards, 86(2), 569-586.

Deori, M., \& Baruah, N. (2014). The Role of Media in pre-cyclone preparedness and postcyclone recovery in South Odisha: An Exploratory study.

Doyle, E. E., McClure, J., Potter, S. H., Becker, J. S., Johnston, D. M., Lindell, M. K., ... \& Coomer, M. A. (2018). Motivations to prepare after the 2013 Cook Strait Earthquake, NZ. International journal of disaster risk reduction, 31, 637-649. vulnerability: a methodology for identifying those at risk to natural hazards (pp. 2-3). Canberra: Geoscience Australia.

Dyregrov, A., Yule, W., \& Olff, M. (2018). Children and natural disasters.

EBSCO

(2019).

Retrieved

from

http://eds.b.ebscohost.com/ehost/search/advanced?vid=1\&sid=03806c2a-c325-4bfd86a9-68048789b7bb\%40sessionmgr101.

EM-DAT, 2019. The Emergency Events Database - Universite Catholique de Louvain (UCL) - CRED, D. Guha-Sapir - www.emdat.be, Brussels, Belgium

Yuzugullu, O. (2003). Earthquake risk assessment for Istanbul metropolitan area. Earthquake Engineering and Engineering Vibration, 2(1), 1-23. 
917 Finnis, K. K., Johnston, D. M., Ronan, K. R., \& White, J. D. (2010). Hazard perceptions and 918

920 Finnis, K., Standring, S., Johnston, D., \& Ronan, K. (2004). Children's understanding of natural 921

922

932 Han, Z., Wang, L., \& Cui, K. (2020). Trust in stakeholders and social support: risk perception 933

938 Haynes, K., Lassa, J., \& Towers, B. (2010). Child-centred disaster risk reduction and climate 939 hazards in Christchurch, New Zealand. Australian Journal of Emergency Management, The, 19(2), 11.

Fothergill, A., \& Peek, L. A. (2004). Poverty and disasters in the United States: A review of recent sociological findings. Natural hazards, 32(1), 89-110.

Frewer, L. (2004). The public and effective risk communication. Toxicology letters, 149(1-3), 391-397.

Graham, J., Shirm, S., Liggin, R., Aitken, M. E., \& Dick, R. (2006). Mass-casualty events at schools: A national preparedness survey. Pediatrics, 117(1), e8-e15.

Hak, D., Nadaoka, K., \& Le Phu, V. (2016). Socioeconomic conditions and perceptions of environmental risks in the Mekong delta, Vietnam. Coastal Management, 44(6), 585605. and preparedness by the Wenchuan earthquake survivors. Environmental Hazards, 114.

Hassan, Z. A., Schattner, P., \& Mazza, D. (2006). Doing a pilot study: why is it essential?. Malaysian family physician: the official journal of the Academy of Family Physicians of Malaysia, 1(2-3), 70. change adaptation: roles of gender and culture in Indonesia. Children in a Changing Climate Working Paper. Brighton: Institute of Development Studies.

Hayward, B. (2012). Children, citizenship and environment: Nurturing a democratic imagination in a changing world. Routledge.

Hitchcock, J. L. (2001). Gender differences in risk perception: broadening the contexts. Risk, $12,179$.

Holzer, T. L. (2000). Implications for earthquake risk reduction in the United States from the Kocaeli, Turkey, earthquake of August 17, 1999 (Vol. 1193). US Government Printing Office.

Hurnen, F., \& McClure, J. (1997). The effect of increased earthquake knowledge on perceived preventability of earthquake damage. Australas. J. Disaster Trauma Stud., (3).

Hyogo Framework for Action (2005). Hyogo Framework for Action 2005- 2015: Building the Resilience of Nations and Communities to Disasters. Retrieved from www. 952 unisdr.org/we/coordinate/hfa

Johnson, R. B., \& Onwuegbuzie, A. J. (2004). Mixed methods research: A research paradigm whose time has come. Educational researcher, 33(7), 14-26. 
Joppe, M. http://www.ryerson.ca/ mjoppe/rp.htm

Kalaça, S., Aytekin, B. A., \& Çalı, Ş. (2007, October). Istanbul'da Depreme Karşı Bireysel Düzeyde Önlem Almayı Belirleyen Faktörler. In 11th National Public Health Congress 959 (pp. 23-26).

Kasperson RE, Renn O, Slovic P et al (2000) The social implication of risk: a conceptual framework. In: kas P (ed) The perception of risk. Earthscan Publications, London, pp 232-245.

Knafl, K. A., Webster, D. C., Benoliel, J. Q., \& Morse, J. M. (1988). Managing and analyzing qualitative data: A description of tasks, techniques, and materials. Western Journal of Nursing Research, 10(2), 195-218.

Krejcie, R. V., \& Morgan, D. W. (1970). Determining sample size for research activities. Educational and psychological measurement, 30(3), 607-610.

Lamson, C. (1983). "I Think They're All Caught up" An Inquiry of Hazard Perception among Newfoundland and Inshore Fishermen. Environment and Behavior, 15(4), 458-486.

Liang, G., \& Zhou, N. (2016). Background and reflections on Gorkha earthquake of April 25, 2015. Natural Hazards, 81(2), 1385-1392.

Lindell M, Whitney D (2000) Correlates of household seismic hazard adjustment adoption. Risk Analysis 20(1):13-25

Lindell, M. K., \& Hwang, S. N. (2008). Households' perceived personal risk and responses in a multihazard environment. Risk Analysis: An International Journal, 28(2), 539-556.

Lindell, M. K., \& Perry, R. W. (2012). The protective action decision model: theoretical modifications and additional evidence. Risk Analysis: An International Journal, 32(4), 978 616-632.

979 Lindell, M. K., Arlikatti, S., \& Prater, C. S. (2009). Why people do what they do to protect

980

981

982

983

984

985

986

987 Mileti DS, Fitzpatrick C (1992) The causal sequence of risk communication in the Parkfield

988

989

990

991 against earthquake risk: Perceptions of hazard adjustment attributes. Risk Analysis: An International Journal, 29(8), 1072-1088.

Merchant, A. (2015). Children and Disaster Education: An Analysis of Disaster Risk Reduction within the School Curricula of Oregon, Texas, and the Philippines.

Miceli, R., Sotgiu, I., \& Settanni, M. (2008). Disaster preparedness and perception of flood risk: A study in an alpine valley in Italy. Journal of environmental psychology, 28(2), 164-173. earthquake prediction experiment. Risk Analysis 12(3):393-400

Mort M, Walker M, Lloyd Williams A, Bingley A \& Howells V. (2016) Final project report for 'Children, Young People and Flooding: Recovery and Resilience', Lancaster University, Lancaster, UK

MTA (2012), Active Fault Map of Turkey, Turkey General Directorate of Mineral Research and Exploration, Ankara (in Turkish). 
Murakami, M., Nakatani, J., \& Oki, T. (2016). Evaluation of risk perception and riskcomparison information regarding dietary radionuclides after the 2011 Fukushima nuclear power plant accident. PLoS One, 11(11), e0165594.

Mutch, C. (2014). The role of schools in disaster preparedness, response and recovery: what can we learn from the literature? Pastoral Care in Education, 32(1), 5-22.

Najafi, M., Khankeh, H. R., Elmi, H., \& Pourvakhshoori, N. (2018). Behavioral, normative and control beliefs about earthquake preparedness: a deductive content analysis study. PLoS currents, 10.

Nunnaly, J. (1978). Psychometric theory. New York: McGraw-Hill.

Ozmen, B. (2000). 17 Ağustos 1999 Izmit Körfezi Depremi’nin Hasar Durumu. Deprem Raporu. Afet İşleri Genel Müdürlüğü Deprem Araştırma Dairesi, TDV / DR 010-53.

Pallant, J. (2013). SPSS survival manual. McGraw-Hill Education (UK).

Palm, R., \& Carroll, J. (1998). Illusions of safety: Culture and earthquake hazard response in California and Japan. Westview Press.

Pan American Health Organization, (2009). Information management and communication in emergencies and disasters: manual for disaster response teams, 26-35

Parham, M., Day, S., Teeuw, R.M., Solana, M.C., \& Sensky, T., 2015 Use of PRISM to evaluate schoolchildren's perceptions of natural hazards and responses to them in Dominica. In: The Psychosomatic Factor in Clinical Practice. 23rd World Congress on Psychosomatic Medicine, Glasgow, 20-22, and 2015: Psychotherapy \& Psychosomatics; 84 (suppl 1):56-57. DOI: 10.1159/000438780.

Paton, D., Anderson, E., Becker, J., \& Petersen, J. (2015). Developing a comprehensive model of hazard preparedness: lessons from the Christchurch earthquake. International Journal of Disaster Risk Reduction, 14, 37-45.

Paton, D., Smith, L., \& Johnston, D. (2000). Volcanic hazards: risk perception and preparedness. New Zealand Journal of Psychology, 29(2), 86-91.

Peacock, W. G., Gladwin, H., \& Morrow, B. H. (2012). Hurricane Andrew: Ethnicity, gender and the sociology of disasters. Routledge.

Peek, L. (2008). Children and disasters: Understanding vulnerability, developing capacities, and promoting resilience-An introduction. Children Youth and Environments, 18(1), $1-29$.

Peek, L., Abramson, D. M., Cox, R. S., Fothergill, A., \& Tobin, J. (2018). Children and disasters. In Handbook of disaster research (pp. 243-262). Springer, Cham.

Perlesz, A., \& Lindsay, J. (2003). Methodological triangulation in researching families: Making sense of dissonant data. International Journal of Social Research Methodology, 6(1), 25-40.

Pilisuk, M., Parks, S. H., \& Hawkes, G. (1987). Public perception of technological risk. The Social Science Journal, 24(4), 403-413.

Proctor, L. J., Fauchier, A., Oliver, P. H., Ramos, M. C., Rios, M. A., \& Margolin, G. (2007). Family context and young children's responses to earthquake. Journal of Child Psychology and Psychiatry, 48(9), 941-949. 
Rahman, M. L. (2019). High School Students' Seismic Risk Perception and Preparedness in Savar, Dhaka. Educational Research and Reviews, 14(5), 168-177.

Reilly, P., \& Atanasova, D. (2016). A report on the role of the media in the information flows that emerge during crisis situations.

Repetti, R. L., Taylor, S. E., \& Seeman, T. E. (2002). Risky families: family social environments and the mental and physical health of offspring. Psychological bulletin, 128(2), 330.

Ronan, K. R., \& Johnston, D. M. (2001). Correlates of hazard education programs for youth. Risk Analysis, 21(6), 1055-1064.

Rüstemli, A., \& Karanci, A. N. (1999). Correlates of earthquake cognitions and preparedness behavior in a victimized population. The Journal of Social Psychology, 139(1), 91-101.

Santos-Reyes, J., Gouzeva, T., \& Santos-Reyes, G. (2014). Earthquake risk perception and Mexico City's public safety. Procedia Engineering, 84, 662-671.

Santos-Reyes, J., Santos-Reyes, G., Gouzeva, T., \& Velazquez-Martinez, D. (2017). Schoolchildren's earthquake knowledge, preparedness, and risk perception of a seismicprone region of Mexico. Human and Ecological Risk Assessment: An International Journal, 23(3), 494-507.

SEGE (2011). Kalkınma Bakanlığı İllerin ve Bölgelerin Sosyo-Ekonomik Gelişmişlik Sıralaması Araştırması. Bölgesel Gelişme ve Yapısal Uyum Genel Müdürlüğü, Ankara.

Sendai Framework for Disaster Risk Reduction (2015). The Sendai Framework for Disaster Risk Reduction 2015-2030. Retrieved from http://www.wcdrr.org/ uploads/Sendai_Framework_for_Disaster_Risk_Reduction_2015-2030.pdf

Sensky, T., \& Büchi, S. (2016). PRISM, a novel visual metaphor measuring personally salient appraisals, attitudes and decision-making: qualitative evidence synthesis. PloS one, 11(5).

Shaw, R., Shiwaku Hirohide Kobayashi, K., \& Kobayashi, M. (2004). Linking experience, education, perception and earthquake preparedness. Disaster Prevention and Management: An International Journal, 13(1), 39-49.

Shiwaku, K., Shaw, R., Chandra Kandel, R., Narayan Shrestha, S., \& Mani Dixit, A. (2007). Future perspective of school disaster education in Nepal. Disaster Prevention and Management: An International Journal, 16(4), 576-587.

Siegrist, M., \& Gutscher, H. (2006). Flooding risks: A comparison of lay people's perceptions and expert's assessments in Switzerland. Risk Analysis, 26(4), 971-979.

Sjöberg, L. (1999). Risk perception by the public and by experts: A dilemma in risk management. Human Ecology Review, 1-9.

Sjöberg, L. (2000). Factors in risk perception. Risk analysis, 20(1), 1-12.

Slovic, P. (1987). Perception of risk. Science, 236(4799), 280-285.

Slovic, P., Flynn, J., Mertz, C. K., Poumadere, M., \& Mays, C. (2000). Nuclear power and the public. In Cross-cultural risk perception (pp. 55-102). Springer, Boston, MA. 
Stentz, J. E., Clark, V. L. P., \& Matkin, G. S. (2012). Applying mixed methods to leadership research: A review of current practices. The leadership quarterly, 23(6), 1173-1183.

Tanner, T. (2010). Shifting the narrative: Child-led responses to climate change and disasters in El Salvador and the Philippines. Children \& Society, 24(4), 339-351.

Taylor, H., \& Peace, R. (2015). Children and cultural influences in a natural disaster: Flood response in Surakarta, Indonesia. International journal of disaster risk reduction, 13, 76-84.

Tekeli-Yeşil, S., Dedeoğlu, N., Braun-Fahrlaender, C., \& Tanner, M. (2010). Factors motivating individuals to take precautionary action for an expected earthquake in Istanbul. Risk Analysis: An International Journal, 30(8), 1181-1195.

Torani, S., Majd, P. M., Maroufi, S. S., Dowlati, M., \& Sheikhi, R. A. (2019). The importance of education on disasters and emergencies: A review article. Journal of education and health promotion, 8.

Tucker, B. E. (2013). Reducing earthquake risk. Science, 341(6150), 1070-1072.

$\begin{array}{lllll}\text { Turkish Statistical } & \text { Institute } & \text { (2019). } & \text { Retrieved }\end{array}$ http://www.turkstat.gov.tr/PreTablo.do?alt_id=1047

Turner, R. H., Nigg, J. M., \& Paz, D. H. (1986). Waiting for disaster: Earthquake watch in California. University of California Press.

United Nations International Strategy for Disaster Risk Reduction (2011, October 13). UNISDR says the young are the largest group affected by disasters. Retrieved from https://www.unisdr.org/archive/22742

USGS (2019). U. S. Geological Survey. "Earthquakes with 50,000 or More Deaths". Retrieved fromhttps://web.archive.org/web/20130507101448/http://earthquake.usgs.gov/earthqu akes/world/most_destructive.php

Vaughan, E. (1995). The significance of socioeconomic and ethnic diversity for the risk communication process. Risk Analysis, 15(2), 169-180.

Walker, M., Whittle, R., Medd, W., Burningham, K., Moran Ellis, J., \& Tapsell, S. (2010). After the Rain-learning lessons about flood recovery and resilience from children and young people in Hull. Final project report for 'Children, Flood and Urban Resilience: Understanding children and young people's experience and agency in the flood recovery process'. Lancaster University: Lancaster, UK.

Wester, F. P. J. (2005). K. Krippendorff, Content analysis. An introduction to its methodology:, 20059780761915447.

White, G. F. (1974). Natural hazards, local, national, global. Oxford University Press.

Xu, D., Peng, L., Liu, S., \& Wang, X. (2018). Influences of risk perception and sense of place on landslide disaster preparedness in southwestern China. International Journal of Disaster Risk Science, 9(2), 167-180.

Yasuda, M., Muramoto, T., \& Nouchi, R. (2018). Assessment of Educational Methods for Improving Children's Awareness of Tsunamis and Other Natural Disasters: Focusing on Changes in Awareness and Regional Characteristics in Japan. Geosciences, 8(2), 47. 
Yildiz A. (2019, June). The role of flood experience on children's perception of risk and preparedness. Poster session presented at the 28th Annual Conference of the Society for Risk Analysis - Europe. Systemic Risks: From Natural Hazards to Cyber Risks. Potsdam, Germany.

Zahran, S., Peek, L., \& Brody, S. D. (2008). Youth mortality by forces of nature. Children Youth and Environments, 18(1), 371-388.

Zhang, N., Huang, H., Su, B., Zhao, J., \& Zhang, B. (2016). Information dissemination analysis of different media towards the application for disaster pre-warning. In Effective Communication during Disasters (pp. 45-80). Apple Academic Press. 